\title{
DIREITOS HUMANOS E DIREITOS ANIMAIS NA TEORIA DAS CAPACIDADES DE MARTHA C. NUSSBAUM
}

\author{
HUMAN RIGHTS AND ANIMAL RIGHTS IN THE MARTHA \\ NUSSBAUM'S CAPABILITIES APROACH
}

\author{
Wesley Felipe de Oliveira* \\ Cinthia Berganwer Pereira**
}

\begin{abstract}
Resumo: $O$ objetivo desse trabalho é apresentar a aplicação que a filósofa Martha C. Nussbaum faz da Teoria das Capacidades, para a questão do direito, dignidade, e justiça para os animais não-humanos. Mais precisamente, trata-se da aplicação da Lista das Capacidades humanas, também para os animais. Nussbaum critica a concepção kantiana de que os animais não possuem dignidade devido a sua natureza irracional e a incapacidade para escolhas morais, assim como as teorias contratualistas que fundamentam a justiça a partir da capacidade de reciprocidade, excluindo, portanto, os animais do grupo de sujeitos aos quais são devidos tratamentos justos. Suas críticas se dirigem ainda à excessiva ênfase que o utilitarismo confere à dor e ao prazer, assim como a satisfação das preferências. Demonstraremos, assim, que conforme as capacidades são negadas para humanos e animais, impedindo o desenvolvimento deles, consequentemente a dignidade Ihes é diminuída e, assim, se torna necessária a estruturação de princípios básicos de justiça para humanos e animais não humanos, traçados a partir das capacidades, a fim de remover os obstáculos que os impedem de se desenvolverem e garantir-lhes uma existência digna e sem humilhação a qual eles tem o direito.
\end{abstract}

Recebido: 07/2017

Aprovado: 11/2017

Palavras-chave: Direitos Humanos; Direitos Animais; Capacidades; Dignidade

\begin{abstract}
The aim of this paper is to present the application of the capabilities approach, from the philosopher Martha C. Nussbaum, to the question of rights, dignity, and justice for nonhuman animals. More precisely, it is the application of the list of human capabilities also for animals. Nussbaum criticizes the Kantian conception, which holds that animals do not have dignity due to its irrational nature and the inability to moral choices. She also criticizes the contractualist theories, as them base the justice on the ability of reciprocity, thus, excluding the animals of the group of subjects which receive the adequate treatment. Her criticism is directed also to the excessive emphasis that the utilitarianism gives to the pain and pleasure, as well as the satisfaction of preferences. So, we will demonstrate that if the capabilities are denied to humans and animals, it undermines their development, and consequently, their dignity is diminished. Thus, becomes necessary to structure the basic principles of justice to human and also to the animals nonhuman, based on the capabilities approach, in order to remove obstacles impeding them of developing themselves and to assure them an existence with dignity and without humiliation, as being their right.

Keywords: Human Right; Animal Right; Capabilities; Dignity
\end{abstract}

\section{Introdução}

O objetivo do presente artigo é analisar a concepção de Martha Nussbaun acerca dos direitos e da dignidade dos animais não-humanos, assim como a aplicação dos princípios de justiça para com eles, a partir da

\footnotetext{
* Doutor em Filosofia pela Universidade Federal de Santa Catarina - UFSC, na área de Ética e Filosofia Política.

** Mestra em Filosofia pela Universidade Federal de Santa Catarina - UFSC, na área de Ética e Filosofia Política.
} 
Capabilities Approach, que será traduzida, aqui, por Teoria das Capacidades. O trabalho será dividido em três partes. Primeiramente, serão apresentadas as críticas que a filósofa dirige às teorias da justiça e às concepções de dignidade baseadas no contratualismo; centradas na capacidade racional, de autonomia e reciprocidade. Em seguida, serão expostas as suas críticas de Nussbaum ao utilitarismo, demonstrando seus alcances e suas limitações. Após apresentarmos essas críticas, analisaremos, em um terceiro momento, em que sentido Nussbaum considera que a teoria das capacidades, desenvolvida juntamente com Amartya Sem, oferece uma melhor orientação para a intitulação dos direitos humanos e de que maneira isso deve ser estendido, também, para se refletir sobre os direitos dos animais, garantindo a eles uma existência com dignidade e sem humilhação. Analisaremos, então, a aplicabilidade da lista das capacidades, (que fundamentam a estruturação de princípios de justiça e de direitos humanos) para os animais não-humanos. Perceberemos, no decorrer do trabalho, de que modo essas concepções envolvendo a fundamentação dos direitos humanos, na teoria das capacidades, acabam por envolver, também, a questão dos direitos animais.

\section{O conceito de dignidade (Kant)}

No capítulo chamado "Beyond 'compassion and Humanity': Justice for Nonhuman Animals", que compõe a obra Frontiers of Justice, a filósofa Martha C. Nussbaum observa o quanto que os seres humanos compartilham o mundo com outros animais. Isso significa que estamos em constante relação com os membros de outras espécies. Essas relações podem inspirar sentimentos de compaixão, simpatia e até mesmo preocupação moral, mas também, muitas vezes, esse relacionamento envolve a manipulação direta da vida e das condições de bem-estar dos animais, assim como a indiferença perante as situações de crueldade praticadas com eles. Portanto, segundo Nussbaum, "parece plausível pensar que estes relacionamentos devem ser regulados pela justiça [...]" (NUSSBAUM, 2007, p. 326, tradução nossa). Ainda na introdução de sua obra, a filósofa considera que a questão dos animais se apresenta como um dos três problemas de justiça social 1 ainda não resolvidos, e, portanto, compreende-se que:

[...] precisamos encarar a questão da justiça envolvida em nosso tratamento dos animais não-humanos. Que animais sofrem dor e indignidade nas mãos humanas tem sido reconhecida como sendo uma questão ética; e mais raramente como sendo uma questão de justiça social. Se reconhecermos isso, [...] fica claro, mais uma vez, que esse novo problema exigirá uma mudança teórica. Imagens da cooperação social e reciprocidade que 
exigem racionalidade em todas as partes, por exemplo, precisará ser reexaminada e novas imagens de um diferente tipo de cooperação inventada (NUSSBAUM, 2007, p. 02, tradução nossa).

Pensar o conceito de existência digna dos animais pode parecer, em primeira análise, uma noção estranha de ser compreendida ou até mesmo inaplicável para o status moral e político dos animais. Na tentativa de se pensar estes conceitos e sua relação com os animais, Nussbaum considera, inicialmente, que a existência digna para um animal não-humano parece incidir, entre tantas coisas, em:

[...] oportunidades adequadas para nutrição e atividade física; liberdade da dor, miséria, e crueldade; liberdade para agir do modo que é característico de sua espécie (ao invés de ser confinado e, como aqui, feito para realizar acrobacias tolas e degradantes); liberdade do medo e oportunidades de interação gratificantes com outras criaturas da mesma espécie, e de espécies diferentes; uma chance de desfrutar da luz e do ar com tranquilidade (NUSSBAUM, 2007, p. 326, tradução nossa).

Nesse sentido, quando humanos agem de modo a negar essas e outras condições básicas para a boa sobrevivência de um animal e, portanto, restringindo a existência de uma vida digna para os animais, isso se apresenta, então, como uma urgente questão de justiça que tem sido negada ao longo da tradição ética e política filosófica, fundamentada, principalmente, na ideia de que é na racionalidade que está a base da dignidade (Kant) e que os princípios políticos de justiça são derivados da concepção de um contrato recíproco entre os iguais (contratualismo/Rawls).

Da concepção kantiana, resultou-se para a posteridade a ideia de que os seres que carecem dessa fonte de dignidade, isto é, da racionalidade, estão fora da comunidade moral e política. Do mesmo modo, os seres incapazes de compreender e participar ativamente da noção de um contrato são também incapazes de participarem de uma comunidade moral. A partir disso, os animais encontram-se na situação de seres não incluídos nas considerações morais e políticas desenvolvidas ao longo da história da filosofia, além de não serem sujeitos merecedores da proteção conferida pelos princípios de justiça.

A teoria de Kant nega que os seres humanos tenham deveres diretos para os animais, pois os deveres morais são dirigidos apenas aos seres racionais e autoconscientes. Como os animais não possuem razão e autoconsciência, eles, por conseguinte, podem ser considerados meros meios para um fim, e este fim é o ser humano.

O homem, e, duma maneira geral, todo o ser racional, existe como fim em si mesmo, não só como meio para o uso arbitrário desta ou daquela vontade. Pelo contrário, em todas as suas acções, tanto nas que se dirigem a ele Problemata: R. Intern. Fil. v. 8. n. 3 (2017), p. 172-195 ISSN 2236-8612 
mesmo como nas que se dirigem a outros seres racionais, ele tem sempre de ser considerado simultaneamente como fim. Portanto, o valor de todos os objectos que possamos adquirir pelas nossas acções é sempre condicional. Os seres cuja existência depende, não em verdade da nossa vontade, mas da natureza, têm contudo, se são seres irracionais, apenas um valor relativo como meios e por isso se chamam coisas, ao passo que os seres racionais se chamam pessoas, porque a sua natureza os distingue já como fins em si mesmos. (KANT, 2007, p. 68).

O único dever que Kant reconhece por parte dos humanos em relação aos animais são os deveres indiretos com a humanidade, pois ele reconhece a possibilidade de ao um indivíduo ser habitualmente cruel com os animais, há nele uma tendência em estender também uma prática cruel com os seres humanos.

[...] não temos quaisquer deveres diretos no que diz respeito aos animais. Os animais não possuem consciência de si. Eles existem apenas como meio para um fim, e não para seu próprio bem, e esse fim é o homem. [...] Os nossos deveres em relação aos animais são apenas deveres indiretos em relação à humanidade. Se um homem abater o seu cão por este já não ser capaz de servi-lo, ele não falha em seu dever para com o cão, pois o cão não pode julgar, mas o seu ato é desumano e prejudica em si essa humanidade que ele deve mostrar aos seres humanos. Para não sufocar os seus sentimentos humanos, ele tem de praticar a generosidade para com os animais, pois quem é cruel para os animais logo se tornará cruel para com os homens. Podemos julgar o coração de um homem pelo modo como ele trata os animais. [...] Quanto mais nos dedicamos a observar os animais e seu comportamento, mais os amamos, vendo quão grande é o seu cuidado com as suas crias, e nesse contexto, não podemos contemplar nem mesmo a crueldade com um lobo. [...] Na Inglaterra, os açougueiros, cirurgiões ou médicos não fazem parte dos doze homens dos júris, pois estão acostumados com a morte. Então, quando anatomistas usam animais vivos nas suas experiências, isso certamente é crueldade, mas o seu objetivo é louvável e podem justificar a sua crueldade, pois os animais são considerados como instrumentos do homem, porém, isso é aceitável apenas se não for por esporte. [...] Assim, todas as obrigações relativas aos animais, aos outros seres e as coisas, têm uma referência indireta aos nossos deveres para com a humanidade. (KANT, 1997, p. 212-213).

Kant não reconhece que animais são seres capazes de dignidade ou dotados de algum valor intrínseco, o que, por sua vez, significa que seu único valor constitui-se meramente como um sendo instrumental. Para Kant o status moral de um ser repousa sobre a sua racionalidade. Não reconhecendo, portanto, essa faculdade nos animais, consequentemente, não se reconhece neles um significativo valor moral. 


\section{Contratualismo (Rawls)}

A outra questão em torno de uma justiça para os animais analisada por Nussbaum, diz respeito ao contratualismo contemporâneo do filósofo norteamericano John Rawls, e, de que modo sua teoria limitou a aplicação dos princípios de justiça apenas para os seres humanos. Rawls reconhece que o fato de animais sentirem prazer e dor nos impõe determinados deveres em relação a eles, deveres estes que ele chama de "compaixão e humanidade" (RAWLS, 2002, p. 569). No entanto, para Rawls, estas não são questões de justiça e a doutrina do contrato não pode ser estendida para os animais.

Em uma seção intitulada "The Basis of Equality", na obra $A$ Theory of Justice, Rawls argumenta que falta aos animais muitas das propriedades que tornam os humanos merecedores de serem tratados de acordo com os princípios da justiça. Ser uma pessoa moral, segundo Rawls, é uma condição suficiente para estar no direito de ser tratado com justiça em uma base de igualdade com os outros. Por pessoa moral, compreende-se a posse de duas características que Rawls denomina de "poderes morais" (moral power) que são: (1) a capacidade para uma concepção de bem e (2) a capacidade para um senso de justiça. (RAWLS, 2002, p. 561). Ambas as características são possuídas, ao menos, em certo grau mínimo. Faltando essas capacidades nos animais, consequentemente, eles são contemplados pela abrangência do princípio de justiça.

[...] eu gostaria aqui de lembrar os limites da teoria da justiça. Não só muitos aspectos da moralidade são deixados de lado, mas também não se oferece nenhuma consideração acerca da conduta correta em relação aos animais e ao restante da natureza. Uma concepção da justiça é apenas uma parte de uma visão moral. Embora eu não tenha afirmado que a capacidade para um senso de justiça é condição necessária para termos direito à justiça, realmente parece que não se exige que concedamos justiça estrita a criaturas que não têm essa capacidade. Mas disso não decorre que não haja exigência alguma relativa a elas, nem nossas relações com a natureza. Certamente, é errado tratar os animais com crueldade, e a destruição de toda uma espécie pode ser um grande mal. A capacidade para sentimentos de prazer e dor e para as formas de vida das quais os animais são capazes impõe deveres de compaixão e humanidade no caso deles. Não tentarei explicar essas convicções ponderadas. Elas estão fora do escopo da teoria da justiça, e não parece possível estender a visão contratualista de modo a incluí-las de um modo natural. Uma concepção correta de nossas relações com os animais e com a natureza parece depender de uma teoria da ordem natural e de nosso lugar dentro dela. Uma das tarefas da metafísica é elaborar uma visão do mundo que seja adequada para esse propósito; ela identificaria e sistematizaria as verdades decisivas para essas questões. É impossível dizer em que medida a justiça como equidade terá de ser 
revisada de modo a enquadrar-se nessa teoria mais ampla. (RAWLS, 2002, p. 568-569, grifo meu).

Nussbaum entende que a concepção de pessoa moral trazida por Rawls e que recebe forte influência de Kant, não exclui apenas os animais, mas também resulta na exclusão dos muitos seres humanos que são afetados por graves deficiências mentais. Nussbaum traz em sua analise o argumento dos casos marginas, muito utilizado por filósofos animalistas como Peter Singer e Tom Regan. De acordo com esse argumento, os critérios frequentemente mencionados para se justificar uma consideração moral apenas para os humanos e negligenciar os animais, acaba por excluir não apenas os animais, mas também os muitos indivíduos de nossa própria espécie, que não apresentarem justamente os critérios que os tornam seres dignos de considerações morais, direitos ou de serem protegidos pelos princípios de justiça. Seguindo essa mesma argumentação, Nussbaum observa que na teoria de Rawls, e, de acordo com os critérios por ele apresentado, não apenas os animais, mas também muitos seres humanos não satisfazem os requisitos exigidos para serem considerado uma pessoa e possuírem, assim, o status moral que lhe é conferido.

A concepção kantiana de pessoa é claramente suficiente, na visão de Rawls, para descartar animais não humanos como membros da comunidade dos que trabalham e estão ligados pelos princípios da justiça. Os dois poderes morais pertencem, na sua visão, somente aos seres humanos, e, mesmo assim, não a todos entre esses. Os animais, assim como os seres humanos mentalmente deficientes, não conseguem ser pessoas no sentido requisitado [...] e tanto a dignidade quanto a inviolabilidade das pessoas também são entendidas em termos de sua participação em uma comunidade moral (NUSSBAUM, 2007, p. 332, tradução nossa).

Outro modo como Nussbaum analisa e critica a posição de Rawls, considera que seus argumentos comentem muito mais um erro empírico do que filosófico, e é sobre esse erro que Rawls (e também Kant) fundamenta a exclusão dos animais não-humanos do escopo da justiça. Segundo a autora: "ele não tem entendido o quão inteligente os animais são, como eles são capazes de relacionamentos (tanto com humanos quanto com outros), envolvendo formas complexas de reciprocidade" (NUSSBAUM, 2007, p. 332, tradução nossa). Para Nussbaum:

[...] a teoria de Rawls é, de fato, empiricamente incompleta. Ele não faz nenhum esforço para estudar a inteligência de animais, e ele não oferece nenhum argumento de que eles são incapazes de reciprocidade 
(NUSSBAUM, 2007, p. 332, tradução nossa).

Embora reconhecendo que existem certos elementos de reciprocidade entre humanos e animais, Nussbaum observa, ainda assim, que isso não ocorre com todos os animais. Se, por um lado, há relação recíproca entre humanos e os animais de estimação, como cães e gatos, por exemplo, o mesmo não pode ser afirmado em relação aos animais silvestres, como os leões e pássaros. No entanto, o tratamento conferido para esses animais também levantam questões de justiça, pois, do mesmo modo que não há reciprocidade com muitos humanos incapazes, e disso não se segue a anulação das obrigações de justiça para com eles, o mesmo ocorre em relação aos animais. A incapacidade de reciprocidade com eles não é razão para excluí-los das questões de justiça.

A questão do contratualismo e da formulação dos princípios de justiça, segundo Nussbaum, podem ser colocadas a partir de duas questões: "Quem estrutura os princípios?" E, "para quem os princípios são estruturados?" (NUSSBAUM, 2007, p. 16, grifo e tradução nossa). Ou seja, se os princípios políticos e as leis são feitas por humanos, como podem os animais se constituírem como sujeitos de justiça quando eles não estão entre aqueles que são capazes de participarem da estruturação dos princípios de justiça? Devido a essa impossibilidade, o contratualismo entende que os animais não podem ser sujeitos de justiça uma vez que eles não podem participar da estruturação de um contrato. No que diz respeito aos seres humanos com tais incapacidades, em função, por exemplo, de alguma doença mental severa, Nussbaum observa que "Rawls está preparado para lidar com seus interesses em um estágio posterior; mas no caso dos animais ele nega por completo que as questões que se apresentam para nós sejam questões de justiça" (NUSSBAUM, 2007, p. 335, tradução nossa).

Para Nussbaum, esta posição de exclusão dos animais da esfera da teoria da justiça feita por Rawls é motivada "tanto por sua concepção kantiana de pessoa quanto pela estrutura da posição do contrato social" (NUSSBAUM, 2007 , p. 335, tradução nossa). Mas, diferentemente de Kant, Rawls, como já destacamos, sustenta que temos alguns deveres morais com os animais, tanto de compaixão, quanto de humanidade; mas a justiça, no entanto, permanece limitada apenas aos seres humanos.

Nussbaum, no entanto, identifica alguns problemas em relação a esses dois elementos - compaixão e humanidade. Ela observa que a emoção da compaixão envolve o pensamento de que outra criatura está sofrendo de modo significativo, mas não há uma responsabilidade (blame) direta por esse sofrimento. O sentimento de compaixão "não envolve o pensamento de que alguém é o responsável por esse sofrimento" (NUSSBAUM, 2007, p. 336, tradução nossa). Podemos, por exemplo, sentir compaixão pela vítima de Problemata: R. Intern. Fil. v. 8. n. 3 (2017), p. 172-195 ISSN 2236-8612 
alguma doença, sem que isso envolva, necessariamente, uma responsabilidade efetiva por seu estado.

Em relação ao sentimento de "humanidade", Nussbaum o toma no mesmo sentido, isto é, ele omite o elemento essencial da responsabilidade por realizar algo errado, e isso é um problema, pois, pensada dessa maneira, os dois sentimentos obscurecem uma importante distinção entre a compaixão sentida por um animal que adoece e morre por uma doença cuja culpa por tal situação sofredora não é de ninguém, e a responsabilidade que temos pelo sofrimento de um ser que é cruelmente tratado por um ser humano.

Nesse sentido, Nussbaum considera relevante introduzir um elemento nessa análise, qual seja: o de que "deveres da compaixão envolvem o pensamento de que é errado causar o sofrimento aos animais" (NUSSBAUM, 2007, p. 336, tradução nossa). Na maioria das relações dos seres humanos com os animais, o sofrimento desses seres é originado diretamente de um ato nocivo por parte dos seres humanos contra sua integridade física. Para Nussbaum, portanto, "um dever da compaixão envolveria o reconhecimento desta injustiça" (NUSSBAUM, 2007, p. 336, tradução nossa), algo não presente na concepção de Rawls. Assim, a autora entende que:

[...] um dever da compaixão não seria somente um dever de ter compaixão, mas um dever como resultado de nossa compaixão, de se abster, inibir e punir atos do tipo que causam sofrimento ocasionando a compaixão (NUSSBAUM, 2007, p. 336, grifo e tradução nossa). ${ }^{2}$

Mas, a questão mais importante aqui reside em compreender o que significa exatamente dizer que os maus-tratos dos animais não são apenas moralmente errados, mas moralmente errados em um sentido especial, ou seja, em um sentido que levanta mais propriamente as questões de justiça. Nussbaum compreende a dificuldade de tal questão, uma vez que os debates sobre justiça envolvem uma variedade de conceitos em torno da definição do que seja exatamente a justiça, a política, os direitos, as considerações éticas, e etc. No entanto, Nussbaum salienta que:

[...] o que nós normalmente queremos dizer quando chamamos um ato mal de injusto é que a criatura prejudicada por este ato tem um direito (entitlement) de não ser tratada dessa maneira, e um tipo básico ou particularmente urgente de direito [...]. A esfera da justiça é a esfera dos direitos básicos (basic entitlements). Quando eu digo que o maltrato de animais é injusto, eu quero dizer não apenas que é errado de nós trata-los desta maneira, mas também que eles têm um direito (right), um direito moral (entitlement), a não serem tratados desse modo. É injusto para com eles (NUSSBAUM, 2007, p. 337, tradução nossa). 
Para Nussbaum, e nisso reside a base de sua teoria das capacidades, se pensarmos nos animais como seres ativos, que possuem um bem, e que juntamente com isto possuem um direito de persegui-lo, ou seja, buscar alcança esse bem, naturalmente isso nos leva a vermos que os danos causados a eles são injustos, pois os impedem de alcançar aquilo que lhes é peculiar.

[...]Pensar os animais como seres ativos que tendem a um bem nos leva a ter a ideia de que eles têm o direito de perseguir esse bem. Se tivermos esse pensamento, é provável que vejamos sérios danos feitos contra eles, impedindo-os de perseguir tal bem, como injustos. (NUSSBAUM, 2007, p. 337 , tradução nossa).

Esses são aspectos importantes trazidos por sua conjectura e que não estão presentes na teoria de Rawls e nem mesmo na de Kant. Ambas as teorias não consideram o sentido de que o animal é, em si mesmo, um agente e um sujeito, uma criatura ativa com quem a humanidade vive em interação, mas a partir de uma interação instrumental, sendo tratados como meros meios para os fins humanos.

O que falta na explicação de Rawls, como na de Kant (apesar de mais sutilmente), é a noção do animal como um agente e um sujeito, como uma criatura a quem algo é devido, uma criatura que em si mesma um fim. [...] o enfoque das capacidades trata os animais como agentes em busca de uma existência plena (flourishing existence); essa concepção básica, acredito, é uma das suas grandes forças (NUSSBAUM, 2007, p. 337, tradução nossa).

Esse será um aspecto importante que a teoria das capacidades levará em conta na sua aplicação em relação aos animais, tomando-os como seres ativos que possuem fins em si mesmos, e que em função disso, são seres que buscam viver uma existência próspera (flourishing existence) e condizente com as peculiaridades de sua espécie.

\section{Utilitarismo}

Ao analisar o utilitarismo, Nussbaum o considera como a teoria que mais tem contribuído para o reconhecimento da importância moral do sofrimento animal e do direito em serem tratados de modo mais compassivo e respeitoso. De certa maneira, no utilitarismo o tratamento justo e adequado, observa Nussbaum, "é buscado para todos os seres sencientes, muitos dos quais não podem participar na estruturação dos princípios" (NUSSBAUM, 2004, p. 302, tradução nossa), superando, assim, uma das dificuldades colocadas pelo 
contratualismo. No entanto, apesar da teoria utilitarista ter contribuído de modo muito mais significativo para a questão da inclusão dos animais no âmbito da ética e da justiça, Nussbaum apresenta alguns problemas nessa teoria e, consequentemente, na sua aplicação em refletir o modo como devemos tratar os animais.

Seguindo as observações de Bernard Willians e Amartya Sen, a autora coloca três aspectos do utilitarismo e os analisa criticamente. São eles: 1) consequencialismo; 2) ranking pela soma (sum ranking) e, 3) hedonismo (ou alguma outra versão sobre o bem, como por exemplo, satisfação das preferências). Analisaremos, a seguir, cada um desses aspectos.

(1) Consequencialismo: esse primeiro aspecto do utilitarismo sustenta que uma ação é correta na medida em que ela promove as melhores consequências. Essa noção é a que gera menos dificuldades, uma vez que as pessoas podem sempre ajustar a preocupação do bem-estar ou o bem, em termos consequencialistas, de modo a admitir muitas coisas importantes que normalmente os utilitaristas não fazem muita ressalva, como a proteção dos direitos, o pluralismo ou heterogenia dos bens, e até mesmo os compromissos pessoais. Nussbaun observa também, que de um modo geral, "qualquer teoria moral pode ser consequencializada, isto é, colocada de uma maneira onde a questão valorizada pela teoria aparece na consideração das consequências produzidas" (NUSSBAUM, 2004, p. 303, tradução nossa).

(2) O segundo aspecto está comprometido com a agregação, e por isso é chamado de ranking pela soma. Esta visão mede os princípios de justiça pelo resultado que eles produzem, não precisando simplesmente adicionar todos os bens relevantes juntos. Eles podem ser pesados de outras maneiras. Podemos, por exemplo, insistir que cada pessoa tenha um direito inalienável de colocar-se acima de um limite de determinados bens essenciais. Além disso, uma visão pode, conforme sustenta Rawls, focalizar sua atenção na situação dos menos favorecidos, recusando permitir que as desigualdades impeçam a pessoa de elevar a sua posição. Esses modos de considerar o bem-estar insistem em tratar as pessoas como fins, o que significa afirmar que o bemestar de algumas pessoas não pode ser alcançado por meio das desvantagens para outras pessoas, ou, mais especificadamente, a busca do bem-estar geral da sociedade como um todo não autoriza a violação dos direitos de um indivíduo e do seu bem-estar, baseada na justificativa de que isto resultará em um aumento significativo do bem-estar da maioria.

Em relação a isso, Nussbaum afirma que o utilitarismo seria negligente, uma vez que, no entendimento da autora, o "utilitarismo notoriamente recusa a separação e a inviolabilidade da pessoa" (NUSSBAUM, 2004, p. 303, tradução nossa). Conforme Nussbaun interpreta o utilitarismo, seguindo as concepções de Bernard Williams e Amartya Sen, haveria uma compatibilidade entre as 
práticas de tortura, escravidão, exploração ao longo da vida com as teorias utilitaristas se ficasse evidente que tais atos acarretarem em um aumento médio ou total do bem-estar geral. Mas, mesmo que os resultados dessas práticas não expressem um aumento total do bem-estar geral, e, portanto, não justificassem tais atos com base no utilitarismo, ainda assim, Nussbaum considera que "a melhor razão para ser contra a escravidão, a tortura, a subordinação ao longo da vida é uma razão de justiça e não um cálculo empírico do total ou da média de bem-estar" (NUSSBAUM, 2004, p. 303, tradução nossa).

Além disso, Nussbaum chama atenção para o fato de que se nos focarmos em outro critério utilitarista, neste caso, a satisfação das preferencias, iremos nos defrontar com o problema que ela denomina de "preferencias adaptativas" (NUSSBAUM, 2004, p. 303; NUSSBAUM, 2007, p. 73, tradução nossa). Nussbaum observa que quando as pessoas, ou até mesmo os animais, se encontram em certas condições, as suas preferências podem ser maleáveis e influenciadas pelas circunstâncias em que elas se encontram, o que pode levá-los a adaptarem suas preferências de acordo com as suas expectativas e possibilidades de satisfazê-las. "Pessoas ajustam suas preferências para o que elas acreditam que possam alcançar, e também ao que sua sociedade lhes diz ser uma realização adequada para alguém como elas." (NUSSBAUM, 2007, p. 73, tradução nossa). Na situação social e cultural das mulheres em algumas partes do mundo, por exemplo, assim como de muitas outras pessoas, cuja vida é, de alguma maneira, privada e limitada pelo peso e influência das tradições, frequentemente é demonstrado que elas possuem preferências, mas que, se bem analisadas, podem se demonstrar como sendo preferências muitas vezes desenvolvidas e possuídas a partir de alguma injusta condição de vida que lhes serve de base ou pano de fundo para as fundamentarem. As mulheres podem, por exemplo, manifestar uma preferência em não querer votar, trabalhar, estudar e etc., mas o que muitas vezes condiciona essas escolhas é determinado por situações culturais e sociais injustas, que as impedem de almejar outras coisas além daquelas que lhes são apresentadas. Juntamente com isso, há também os problemas relativos às preferências originadas a partir de informações errôneas, equivocadas ou maliciosas, além daquelas induzidas pelo medo.

Em relação aos animais isto pode ser observado no experimento conhecido como desamparo apreendido, realizados intensamente na década de 60 pelo psicólogo Martin Seligman. O experimento consistia em induzir estados de desespero e desamparo nos animais, cães em sua maioria, condicionando-os a perderem as esperanças em esforçar-se para fugirem das dores, originadas a partir dos choques elétricos, devido à gradual dificuldade imposta pelos obstáculos colocados pelo pesquisador a cada nível da indução 
de eletrochoques. O experimento era realizado até o momento em que ficavam totalmente inertes ao receberem os estímulos dolorosos.

Os animais criados e mantidos em cativeiro podem ficar impedidos de reaprender a viver na selva e, não possuírem, portanto, uma preferência pelo seu estado natural, ou apresentarem as mesmas preferencias que são manifestadas por outros animais da mesma espécie que vivem no seu habitat natural. Os animais adestrados e utilizados em espetáculos circenses, por exemplo, são induzidos a apresentarem muitas preferências contrárias a sua natureza específica, com base na submissão e na indução pelo medo. Esses são alguns exemplos de casos de "preferências adaptativas" e que demonstram as dificuldades encaradas pelo utilitarismo em aplicar o conceito de preferência, tanto em relação aos humanos, quanto aos animais.

(3) O terceiro aspecto do utilitarismo analisado por Nussbaum, diz respeito ao hedonismo. Segundo a autora, o conceito de prazer é uma noção enganosa e difícil de ser definida. Os principais filósofos utilitaristas debateram profundamente sobre se esta noção é, por um lado, centrada em sua intensidade e duração das sensações (Bentham), ou, por outro lado, se os prazeres se diferenciam por suas distinções qualitativas, como as atividades a eles associadas (Mill). Para Nussbaum, concentrarmos nossa atenção apenas para a dor e o sofrimento para medir uma quantidade de bem, é uma estratégia muito limitada, pois tal procedimento omite o valor que damos a muitas outras atividades que não estariam diretamente e essencialmente vinculadas ao prazer. Em relação aos animais, a autora observa que: "parece haver coisas valiosas na vida de um animal que não seja o prazer, como o livre movimento, a conquista física e também o sacrífico altruísta para o parentesco e grupo" (NUSSBAUM, 2004, p. 304, tradução nossa). Juntamente com isso, outra questão problemática que Nussbaum identifica neste aspecto se refere ao fato de existirem os prazeres ruins, como por exemplo, o prazer experimentado pela plateia de um circo ou de uma tourada em contemplar a submissão, perseguição e morte do animal. Para Nussbaum, "não está claro se tais prazeres devem até mesmo contar positivamente no cálculo social" (NUSSBAUM, 2004, p. 304, tradução nossa).

A visão utilitarista, tomada em seu conjunto, está muito vulnerável a questão de números e, por isso, não é capaz de dar uma resposta à objeção contida no argumento da substituição ou da não-existência. Tal argumento sustenta que: se é algo bom trazer à vida os seres, justamente devido ao prazer que sentirão, então, por exemplo, a indústria da carne é uma prática favorável aos animais, pois ela faz com que animais sejam trazidos à existência em incontáveis quantidades, animais estes que nunca teriam existido se não fosse para o propósito de serem comidos, e, portanto, jamais sentiriam os prazeres que experimentarão em vida. Mesmo que alguns animais sejam 
mortos, a morte de uns resulta no nascimento de outros, isto é, na substituição por novos animais que não teriam existido se os anteriores não fossem mortos, mantendo, assim, sempre um total de utilidade, ou seja, de experiências prazerosas e positivas existindo no mundo. ${ }^{3}$

A partir dessas razões, portanto, Nussbaum rejeita o utilitarismo, e observa que:

[...] o utilitarismo tem grandes méritos, mas também grandes problemas. Consequencialismo está em tensão com o respeito liberal para uma pluralidade de concepções do bem. Ranking pela soma trata alguns como meios para os fins dos outros. Utilitarismo hedonista e de preferência apaga a heterogeneidade e a distinção do bem, ignora os bens que não residem na senciência, e falha ao criticar as preferências e prazeres desenvolvidos sob condições historicamente injustas (NUSSBAUM, 2007, p. 346, tradução nossa).

Apresentaremos, agora, a teoria das capacidades desenvolvida por Nussbaum, juntamente com Amartya Sen, e sua aplicação na questão dos animais não-humanos. Será analisado de que modo as características desta teoria podem superar muitos desses problemas até aqui apresentados.

\section{A Teoria das Capacidades}

A teoria das capacidades, no modo como é desenvolvida por Nussbaum, recebe importantes influências por parte do pensamento de Aristóteles, ao considerar que é uma perda e uma tragédia "quando uma criatura viva, com uma capacidade inata ou 'básica' para algumas funções que são avaliados como importantes e bons, nunca tenha a oportunidade de desempenhar essas funções" (NUSSBAUM, 2007, p. 346-347, tradução nossa). Pensando dessa maneira, os fracassos em relação à uma educação eficiente, à promoção adequada dos cuidados com a saúde, à liberdade de expressão, consciência, e etc., são entendidos como causas que comprometem o florescimento (flourishing) e o desenvolvimento das capacidades que as pessoas possuem, e que são tomadas como valiosas e admiráveis. Para. Nussbaum, o enfoque das capacidades humanas pode ser entendido como "o que as pessoas são na verdade capazes de fazer e de ser", ou um "funcionamento (functioning) autenticamente humano" (NUSSBAUM, 2007, p. 70-71, tradução nossa) - a partir do qual se pode levar ao desenvolvimento de uma teoria da justiça social superior e mais eficiente do que o enfoque oferecido pela teoria contratualista ou utilitarista.

Um dos aspectos importantes da teoria das capacidades repousa sobre o pensamento de que os seres humanos devem ter a chance de prosperar, isto é, florescer segundo o seu próprio modo, estando protegidos das interferências 
prejudiciais por parte dos outros. Pelo fato das capacidades serem essenciais para a existência de uma vida humana com dignidade, há uma forte razão, portanto, para promover o florescimento delas e remover os obstáculos que as impedem de serem desenvolvidas. Para Nussbaum, a dignidade humana está diretamente relacionada com as capacidades, o que faz delas algo fundamental para o estabelecimento de princípios políticos que estejam focados justamente na preocupação com o desenvolvimento das capacidades, para garantir ao indivíduo uma vida digna e próspera.

Nussbaum compreende que as capacidades devem ser buscadas pelas pessoas, e isso significa que cada indivíduo deve ser tratado com um fim em si mesmo, e não como um mero meio, isto é, como um mero instrumento do fim dos outros. Há um determinado nível limiar de cada capacidade e sob o qual se sustenta um funcionamento verdadeiramente humano. Isso faz com que e os objetivos sociais ou princípios de justiça devam ser pensados e buscados em termos de garantir a obtenção deste nível limiar da capacidade para os cidadãos. A partir disso, Nussbaum relaciona, então, as capacidades básicas com a dignidade, mas também com a falta dela, isto é, com a humilhação. Ser desprovido, limitado, impedido de realizar suas capacidades significa, portanto, a diminuição da dignidade e a inserção em um estado de humilhação. ${ }^{4}$

\section{A Lista das Capacidades}

A partir dessa ideia, Nussbaum tenta justificar uma lista de dez capacidades entendidas como centrais e requeridas para a existência de uma vida humana que seja próspera, com dignidade e sem humilhação. Os elementos da lista das capacidades podem ser tomados como objetivos gerais a serem promovidos e buscados por uma sociedade, garantindo, deste modo, uma justiça básica, ou seja, um mínimo social básico, fixando um padrão a sob o qual os princípios devem partir para que cada cidadão alcance uma vida com dignidade. É importante salientarmos que a autora não toma a lista como estando acabada e definitiva, mas justamente o contrário, estando ela sujeita a constantes reformulações e melhoramentos. Apresento a seguir, e de modo resumido, cada uma destas capacidades que formam a lista:

1 - Vida: ser capaz de viver até o fim de uma vida normal, sem morrer prematuramente ou ter sua vida tão reduzida a ponto de não valer a pena viver.

2 - Saúde Física: ser capaz de ter uma boa saúde, o que significa possuir uma alimentação adequada e abrigo para se proteger apropriadamente.

3 - Integridade Física: ser capaz de movimentar-se livremente de um lugar para outro; estar seguro contra a violência, o abuso sexual, e a violência 
doméstica; ter oportunidade de reprodução e satisfação sexual.

4 - Sentidos, Imaginação e Pensamento: ser capaz de usar os sentidos, imaginar, pensar e raciocinar; fazer as coisas a partir de um modo informado, cultivado e com educação adequada. Ser capaz de usar estas capacidades para experimentar ou realizar obras de sua escolha, seja artística, musical, religiosa, literária, e manifestá-las livremente e com respeito. Ser capaz de viver experiências agradáveis e evitar as situações de dor que não resulte em nenhum benefício para si.

5 - Emoções: ser capaz de estar envolvido com coisas e pessoas, para amar e ter relações de cuidado e afeto, lamentar a ausência dos outros, e, de um modo geral, amar, sofrer, experimentar saudade, gratidão ou raiva justificada. Não ter um desenvolvimento emocional marcado pelo medo ou ansiedade.

6 - Razão Prática: ser capaz de formar uma concepção do bem e realizar um pensamento crítico sobre a própria vida, planejando-a de acordo com suas reflexões e concepções, tendo a proteção para exercer a liberdade de consciência e escolha religiosa.

7 - Filiação: a) ser capaz de viver com e para os outros, envolver-se em várias formas de interação e imaginar-se no lugar de outro; $b$ ) ter as bases sociais do autorrespeito e da não humilhação, ser tratado com um ser digno, cujo valor seja igual aos dos outros. Isso significa estar protegido contra discriminações raciais, sexuais, étnicas, religiosas, assim como, de classe social, nacionalidade, e etc.

8 - Outras Espécies: ser capaz de viver com preocupação em relação aos animais, plantas e com a natureza.

9 - Atividades (Play): ser capaz de rir, brincar e desfrutar de atividades recreativas.

10 - Controle sobre o próprio ambiente: a) político: ser capaz de participar das escolhas políticas que governam a vida; ter o direito à participação política, ter proteção da liberdade de expressão e associação; b) material: ser capaz de manter a propriedade, ter o direito de procurar emprego, adquirir propriedade em igualdade com os outros e de participar de associações.

Quando as capacidades não são garantidas para todos os cidadãos, ao menos em um nível apropriado, significa que há uma ineficiência nos princípios de justiça. A ideia básica sustentada em cada uma dessas capacidades é a de que podemos pensar que uma vida sem as capacidades em questão é uma vida humana sem dignidade. Segundo a autora, a teoria das capacidades resulta em "uma espécie de teoria dos direitos humanos, e direitos humanos tem frequentemente sido ligado de um modo similar à ideia de dignidade humana" (NUSSBAUM, 2007, p. 78, tradução nossa). 


\section{A teoria das capacidades aplicada aos animais não-humanos}

Conforme observamos, a teoria das capacidades, no modo como é desenvolvida e aplicada por Nussbaum, busca trabalhar as questões básicas da justiça e dos direitos, a partir da noção de certo nível de capacidade, que uma vez alcançado, torna a vida digna. Para a filósofa, essa teoria é capaz de oferecer melhor orientação, tanto política quanto moral, do que a oferecida pelo contratualismo e utilitarismo, seja para as questões humanas, seja para a questão dos animais, porque, diferentemente das outras duas, a teoria das capacidades possuí a vantagem de ser:

[...] capaz de reconhecer uma ampla variedade de tipos de dignidade animal e da necessidade correspondente de florescer (flourishing), e porque é atenta à variedade de atividades e objetivos que criaturas de muitos tipos buscam, a teoria é capaz de conceber normas de justiça interespécies que são sutis e exigentes, envolvendo direitos fundamentais para as criaturas de diversos tipos (NUSSBAUM, 2007, p. 327, tradução nossa).

A teoria das capacidades começa com a noção de dignidade e de vida valiosa. Quanto mais as capacidades são satisfeitas, mais digna e valiosa é a vida de uma pessoa. Em contraste, quanto menos realizadas, menos próspera e valiosa está sendo a vida de uma pessoa e, portanto, mais humilhante de configura a sua situação.

Em relação aos animais, a autora compreende que tal concepção "pode ser estendida para fornecer uma base mais adequada para os direitos dos animais do que as outras duas teorias em consideração" (NUSSBAUM, 2004, p. 305, tradução nossa). Assim, a autora analisa se "podemos usar a base humana da teoria das capacidades para traçar, em uma forma geral e experimental, alguns princípios políticos básicos que podem orientar a lei a e política publica ao lidar com animais" (NUSSBAUM, 2007, p. 392, tradução nossa). Os animais são entendidos pela abordagem das capacidades como seres vivos que também são ativos e dotados de uma vasta gama de capacidades para funcionamentos que Ihes são essenciais para uma vida próspera, valiosa e com dignidade.

É importante observar, segundo Nussbaum, que os direitos conferidos aos animais são específicos de cada espécie e baseados sobre as suas formas características de vida e de florescimento (flourishing). Cada animal está inserindo dentro do que a autora chama de uma norma da espécie, isto é, um padrão de existência que é comum a todos os animais de uma espécie (NUSSBAUM, 2007 p. 347). Por isso, a autora enfatiza a importância do conhecimento científico a respeito das espécies animais, pois, com esse 
conhecimento, é possível compreender as necessidades de cada animal, para melhor orientar a reflexão a respeito do apropriado tratamento ético-político que Ihe deve ser conferido (OLIVEIRA, 2017, p. 170).

A seguir, apresentaremos a aplicação da lista das capacidades aos animais. Ao fazer essa extensão, citaremos diversos casos e práticas feitas aos animais, demonstrando de que modo elas os submetem a uma limitação de suas capacidades, o que gera, portanto, uma situação que se configura como um estado de humilhação.

1 - Vida: na teoria das capacidades, os animais possuem o direito de continuarem suas vidas, tendo ou não algum tipo de interesse consciente sobre isso. Todos os animais sencientes têm um direito de estarem assegurados contra a matança gratuita em esporte. Matar animais para confecção de itens de luxo como casacos de peles entra nesta categoria, e deve ser banida, assim como os processos industriais de criação e abate de animais para alimentações. Por respeito à capacidade de sofrer que pode tornar uma vida animal normal inviável, é concebível uma espécie de "paternalismo respeitoso" (NUSSBAUM, 2007, p. 393, tradução nossa), que apoie a realização dos procedimentos de eutanásia nos animais que se encontram em um estado de doença incurável e intratável, ou de dor irreversível que comprometa a qualidade de sua vida.

2 - Saúde Física: um dos direitos mais centrais para os animais é o direito a uma vida saudável. Nas situações em que os animais estão diretamente vivendo sobre controle humano algumas medidas políticas ficam implícitas: leis banindo tratamento cruel e a negligência, assim como o confinamento e os maus tratamentos aos animais na indústria da carne, da pele e demais áreas; leis proibindo o severo e cruel uso de animais de trabalho, incluindo animais de circo; leis regulamentando ambientes nos quais os animais vivem por terem sido resgatados de condições de maus tratos, ordenando a nutrição adequada a eles e a manutenção de espaços que lhes sejam adequados.

Leis como estas já existem em muitas democracias, embora não sejam efetivamente fiscalizadas e cumpridas na prática, e seus infratores não são punidos com eficiência. ${ }^{5}$ Além disso, há uma falta de simetria nas práticas em que os animais criados para alimentação não são protegidos por leis contra maus tratos e crueldade, do mesmo modo são outros animais, exóticos, de estimação ou que estão em ameaça de extinção. Esta assimetria deve ser eliminada pela abordagem das capacidades e a proteção deve se aplicar a todos os animais.

3 - Integridade Física: de acordo com a teoria das capacidades, os animais têm um direito contra a violação de sua integridade física por meio da violência, do abuso, da manipulação e demais formas de tratamento prejudicial 
- independentemente desse tratamento ser ou não diretamente doloroso. 0 procedimento cirúrgico de amputar, nas juntas, as garras dos gatos (declawing) impedindo de suas garras de crescerem, seria banida, pois isto impede o gato de agir conforme sua própria natureza e características. Outros tipos de mutilações, praticadas com finalidades estéticas para agradar os seres humanos, como o corte de caudas e orelhas, seriam também consideradas inapropriadas e proibidas, pois são uma violação da integridade física do animal. Em relação à castração de animais (gatos e cães principalmente), uma medida para resolver o problema da superpopulação de animais, principalmente originada de abandono, Nussbaum considera que tal procedimento deve ser cuidadosamente analisado caso por caso, devendo ser realizada apenas na medida em que isso beneficie o animal ou se apresente como a única medida eficaz para evitar que futuros animais venham a existir sem condições de levarem uma vida com os cuidados e sem sofrimento.

4 - Sentidos, Imaginação e Pensamento: No que diz respeito aos humanos essa capacidade cria uma vasta gama de direitos, como: educação apropriada; liberdade de expressão, tanto artística quanto religiosa; estar livre de estados dolorosos e ser capaz de ter experiências prazerosas. Em relação aos animais este último ponto é o mais óbvio. Se por um lado, a característica da religião ou expressão artística não faz parte da vida dos animais, não existindo para eles, portanto, a necessidade desse tipo de direito, por outro lado, é óbvia a necessidade que os animais possuem em usufruir os estados prazerosos e evitar os dolorosos. Isso constitui uma parte importante da vida animal, e implica, portanto, de acordo com a teoria das capacidades, que devem ser implementadas leis que eliminam os tratamentos severos, cruéis e abusivos, e que assegure aos animais suas fontes de prazer, como a liberdade de movimento em seu ambiente natural que estimula e agrada os sentidos. $\mathrm{Na}$ prática, isso significa banir a caça e a pesca por esporte, que inflige dor e morte nos animais, assim como os métodos de confinamento. Proteger esta capacidade, também significa proteger o ambiente natural do animal.

5 - Emoções: os animais são dotados de uma grande gama de emoções. A grande maioria dos animais sencientes manifestam sentimentos de medo. Muitos também são capazes de experimentar e manifestar intensos comportamentos de fúria, ressentimento, gratificação, aflição, alegria, e alguns até mesmo manifestam compaixão por outro animal em sofrimento. Pela teoria das capacidades, portanto, os animais têm o direito de manterem ligações com outros animais de sua espécie, e com quem podem ter relações de afetos e cuidados, e terem a proteção para que essas ligações não sejam comprometidas e impedidas de serem realizadas, por isolamento ou inflição deliberada de medo. Isso é facilmente entendido em relação aos animais domésticos, mas, estranhamente e, incoerentemente, tais considerações e 
proteções não se estendem para os animais selvagens, àqueles mantidos em cativeiros, zoológicos, circos, os criados para o consumo alimentar ou usados em pesquisas. A grande maioria desses animais têm sua vida emocional negligenciada pelas ações humanas.

6 -Razão Prática: no caso dos seres humanos esse é um direito fundamental. Assegurá-lo, significa que cada humano tem o direito de buscar em sua vida os seus próprios fins estabelecidos. No caso dos animais, no entanto, não há uma analogia precisa em relação a essa capacidade. Mas, é preciso se questionar até que ponto uma criatura tem a capacidade de estruturar objetivos e projetos sob os quais planeja a sua vida. Na medida em que esta capacidade estiver presente em algum animal, ela deve ser apoiada, e isso requer muitas das leis e princípios políticos já sugeridos pela quarta capacidade: espaço adequado para movimento, oportunidade para variações de atividades, etc.

7 - Afiliação: em relação aos humanos, esta capacidade é dividia em duas partes: uma interpessoal, que é a capacidade de viver com e para os outros, e uma de caráter mais público, focada no autorrespeito e na não humilhação. Essas duas partes são também pertinentes em relação aos animais. Eles têm direito à oportunidade de formar e manter vínculos, e envolver-se de forma característica com os outros de sua espécie. Ao mesmo tempo, também possuem o direito de viver em uma cultura política mundial que os respeitem e os tratem como seres dignos. Isso não significa a proteção apenas contra os casos de humilhação que eles vão sentir como dolorosos. De acordo com a teoria das capacidades, os animais têm o direito de estarem em um mundo político que lhes confere direitos políticos e o status legal de seres dignos, independentemente de serem capazes ou incapazes de compreenderem ou reivindicarem este status. Assim como a incapacidade de muitos humanos em compreenderem os seus próprios direitos não é uma razão para deixar de protegê-los, o mesmo acontece em relação aos animais. O modo como os humanos lidam com os seres de outras espécies deveria ser regulada por uma atenção respeitosa a cada membro da espécie, segundo a noção de que cada animal é merecedor de uma vida próspera e livre de tudo aquilo que a impede de se desenvolver.

8 - Outras Espécies: Se os seres humanos possuem o direito de viverem com preocupação em relação aos outros animais, plantas e o mundo natural em geral, então, os animais também possuem o direito de se relacionar com outras espécies, incluindo a humana. Esta capacidade é presente tanto em relação os humanos quanto aos não-humanos.

9 - Atividades (Play): Essa capacidade é obviamente central para a vida de todos os animais sencientes e está relacionada com as mesmas políticas que já foram apresentadas anteriormente: proteção e espaços adequados, 
habitat estimulante para sensações prazerosas, e acima de tudo, a presença de outros membros da espécie para relacionar-se.

10 - Controle sobre o ambiente: para humanos esta capacidade possui duas partes: a política e a material. A primeira é definida em termos de cidadania ativa e o direito de envolver-se na participação política. Em relação aos não-humanos, uma das coisas importantes que esta capacidade coloca, diz respeito aos animais fazerem parte, isto é, estarem incluídos dentro de uma concepção política que é estruturada de modo a respeitá-los, e que está comprometida a tratá-los com justiça. Nesse sentido, os animais possuem direitos, ainda que para que sejam garantidos e respeitados, haja a necessidade de um tutor humano para reivindicá-los no tribunal, tal com é feito com as crianças e muitos outros indivíduos incapazes de reivindica-los. A parte material, na sua forma humana, inclui certos tipos de proteção do direito de propriedade, ao emprego, incluindo o direito para realizar associações. Em relação aos animais, a analogia com o direito de propriedade é interpretada por Nussbaum como um respeito à integridade territorial de seu habitat, seja ele doméstico ou selvagem.

É importante compreender o fato de que esta lista não deva ser tomada como consumada. Isso significa que ela é aberta e sujeita a complementações e modificações, podendo ser aprimorada ao longo do tempo. A teoria das capacidades, conforme desenvolve Nussbaum:

[...] sugere que é apropriado para as nações incluírem em suas constituições e outras declarações de princípios fundamentais, um compromisso com os animais como sujeitos de justiça política e um compromisso de que os animais serão tratados com dignidade (NUSSBAUM, 2004, p. 317, tradução nossa).

A partir da lista das capacidades, compreende-se que quando os animais são colocados em situações nas quais: o seu tempo de vida é deliberadamente reduzido; o curso normal de sua vida é interrompido de um modo abrupto por meio de práticas esportivas, como a caça; são mortos para serem usados como itens de luxo, como casacos de pele ou sapatos; criados e confinados em espaços apertados para serem mortos e utilizados como alimentos; tratados de modo cruel e negligente em relação às suas necessidades físicas ou nutricionais; exibidos em degradantes espetáculos de circos e rodeios onde são obrigados a realizarem atividades contrárias a sua natureza específica e que jamais realizariam na vida natural; quando as partes de seus corpos são amputadas para fins estéticos e experimentais de seres humanos; privados da liberdade de movimento e isolados de seus ambientes originais e de suas fontes naturais de prazer e satisfação específicas de sua própria espécie; colocados em situações que originam sensações e emoções 
de medo, raiva, pânico, fúria; sendo privados das relações com outros animais de sua espécie ou de outras, com quem podem manter relações naturais estreitas e de acordo com as necessidades peculiares de sua espécie, como prover sua prole e desfrutar do convívio com outros animais - se configuram situações nas quais as capacidades para o florescimento são negadas e, portanto, são situações nas quais eles estão submetidos em um estado humilhante, tendo sua dignidade diminuída, negada, violada e desprotegida, sendo tratados meramente como um mero meio puramente instrumental para os fins humanos.

Ao estruturarmos os princípios de justiça e dos direitos aos animais, de acordo com as capacidades, protegendo-os dessas situações mencionadas acima e de muitas outras, estaremos resguardando-os, portanto, contra estados de humilhação e garantindo-Ihes uma existência digna e florescida que Ihes é de direito. As capacidades se tornam, portanto, um critério prático para se avaliar as condições dos animais e o que, mais precisamente, precisa ser levado moral e politicamente em conta quando estabelecemos princípios de justiça que sejam abrangentes.

Uma vez que os humanos vivem uma inter-relação com os animais de outras espécies, o que significa, na maioria das vezes, uma relação que os prejudicam e os submetem em situações que não estariam se não fosse pela conduta humana, é necessário pensarmos a estruturação e a aplicação prática e eficiente de princípios e leis que regulamentem essas relações de modo a não impedir que os animais floresçam segundo as suas capacidades.

\section{Considerações finais}

Nussbaum conclui que a busca por uma justiça global é caracterizada pela inclusão de muitas pessoas, ou grupos, que, conforme a história mostra, não foram previamente incluídos como sujeitos igualmente merecedores de justiça, e em função disso tiveram uma longa história de exclusão, negligência e forte opressão, como é o caso dos pobres, das classes mais baixas, membros de minorias religiosas, raciais, étnicas, e mais recentemente, as mulheres, os portadores de deficiências físicas e mentais, e os habitantes de nações distantes. Ao longo dos séculos é possível identificar a inclusão dessas pessoas ou grupos no escopo das teorias e princípios éticos, políticos, de justiça e de direito.

Mas, para a autora, essa busca pela inclusão não deve estar encerrada apenas nos limites da nossa espécie. Ela deve manter esta marca da expansão e inclusão, e inserir em seus princípios os animais não-humanos, que apesar de serem membros de outras espécies, também são dotados, em suas próprias 
maneiras, das capacidades, e estão constantemente vulneráveis aos desdobramentos de nossas ações sobre eles, que na maioria das vezes os impedem de terem uma existência digna e próspera. Nussbaum compreende que:

[...] uma justiça verdadeiramente global exige não apenas que nós olhemos em todo o mundo para outros membros das mesmas espécies que tem direito a uma vida decente. Ela também exige que olhemos tanto em nossa própria nação como ao redor do mundo para outros seres sencientes com cujas vidas nossa própria vida está inextricavelmente e complexamente interligadas (NUSSBAUM, 2007, p. 406, tradução nossa).

A teoria das capacidades possui, em comparação as outras duas contratualismo e utilitarismo, a vantagem de ser mais sensível a cada forma especifica de vida animal, e assim é capaz de oferecer uma proposta que faz justiça com a variedade e a complexidade da vida dos animais e os seus esforços para florescerem e viverem de modo a não serem impedidos de realizarem aquilo que é de acordo com sua própria natureza. Segundo Nussbaum, este é um importante aspecto que torna este modelo uma parte importante de uma teoria da justiça completamente global, que garanta os direitos de todos os habitantes da Terra, sejam eles humanos ou não-humanos. Manter os direitos para uns e negar para outros, quando os seres de ambas as espécies compartilham essas importantes capacidades que lhes confere uma vida com dignidade, é perpetuar um estado de injustiça que deve ser corrigida, tal como muitas outras injustiças que ficaram marcadas na história, tanto por sua longa existência quanto por sua superação. Os direitos humanos e os direitos dos animais não são duas coisas distintas, mas antes, duas coisas que estão e estreita relação.

\section{Referências bibliográficas:}

KALSING, Rejane Shaefer. Deveres com respeito à natureza enquanto deveres indiretos para os seres humanos em Kant. In: Revista Opinião Filosófica, v.3; n.1, 2012.

KANT, Immanuel. Fundamentação da Metafísica dos Costumes. Tradução de Paulo Quintela. - Lisboa: Edições 70, 2007.

. Lectures on ethics. Cambridge University Press, 1997.

NUSSBAUM, Martha C. Frontiers of Justice: disability, nationality and species membership. Harvard University Press, 2007. 
Beyond "Compassion and Humanity": Justice for Nonhuman Animals. In: Animal Rights: Current Debates and New Direction. Edited by: Cass R. Sunstein and Martha C. Nussbaum, Oxford University Press, 2004, p. 299-320.

OLIVEIRA, Wesley Felipe de. O Princípio da Igual Consideração das Capacidades. 2017. 332f. Tese (Doutorado em Filosofia). Universidade Federal de Santa Catarina, Centro de Filosofia e Ciências Humanas. Florianópolis, 2017.

PINZANI. Alessandro. Reconhecimento e Solidariedade. In: Revista Etich@, vol. 8, n.3, p. 101-113. Florianópolis, Maio, 2009.

RAWLS, John. Uma Teoria da Justiça. Tradução de Almiro Pisetta e Lenita Maria Rímoli Esteves. 2a ${ }^{a}$ ed. - São Paulo: Martins Fontes, 2002. - (Coleção justiça e direito).

REGO; Walquiria Leão; PINZANI, Alessandro. Vozes do Bolsa Família: autonomia, dinheiro e cidadania. São Paulo: Editora UNESP, 2013.

SEN, Amartya. Capability and Well-Being. In: The Quality of Life. Ed. Martha C. Nussbaum and Amartya Sen. Oxford: Clarendon Press, 1993, p. 30-53.

SINGER, Peter. A Response to Martha Nussbaum: reply to Martha Nussbaum, 'Justice for Non-Human Animals'. In: The Tanner Lectures on Human Values, November 2002.2 Disponível em: http://www.utilitarian.net/singer/by/20021113.htm.

WILLIAMS, Bernard. A Critique of Utilitarianism. In: J. J. C. Smart and Bernard Williams, Utilitarianism: For and Against. Cambridge: Cambridge University Press, 1973, p. 77-150.

\footnotetext{
1 Os outros problemas ainda não resolvidos, segundo Nussbaum, referem-se à questão das pessoas física e mentalmente incapacitadas e a extensão da justiça para todos os cidadãos do mundo, principalmente no que se refere às nações menos desenvolvidas econômica e socialmente.

2 Podemos interpretar esta tese de Nussbaum, como sendo um dever de: evitar, inibir e punir atos que são capazes de nos causar compaixão, pois se tal sentimento nos é originado, ele é uma indicação de que algo danoso e prejudicial foi causado a outro ser e do qual estamos reconhecendo como danoso, e, portanto, nos compadecemos com ele.

${ }^{3}$ De acordo com Oliveira: "Embora este argumento seja uma objeção ao utilitarismo, ele só faz sentido quando satisfeitas algumas condições, quais sejam: a) que o animal realmente tenha uma vida prazerosa, sendo criado livre e não em confinamento; b) sua morte seja rápida e indolor; c) sua morte não provoque
} 
sofrimento para os outros animais que permanecerão vivos; d) o novo animal substituído tenha as mesmas condições do animal morto, isto é, as mesmas condições de prazer. Além disso, é importante mencionar que tal argumento se aplica apenas aos animais que não são dotados de certas características peculiares como memória, noção de passado, presente e futuro, autoconsciência, etc. Essas características fazem com que sua morte não seja compensada por se trazer à vida um novo ser. $O$ argumento da substituição pode se mostrar uma forte tese teórica e ideal, mas pouco aplicável na prática. No entanto, a perspectiva das capacidades não se depara com tal problema da substituição, uma vez que vê na vida individual de cada animal um fim em si mesmo e cujo bem não pode ser substituído trazendo outro indivíduo à existência" (OLIVEIRA, 2017, p. 88-89).

4 Como bem expõe Rego e Pinzani: "Ao dispor destas capacidades, o indivíduo consegue assumir a responsabilidade pela própria vida. Há uma relação estreita entre a falta destas capacidades básicas e a humilhação: quem não disponha delas possui boas razões para sentir-se humilhado, como diria Margalit. Cabe salientar que este estado de humilhação não é imputável às pessoas humilhadas, que não são responsáveis por ele: na maioria dos casos elas nascem nele ou foram colocadas forçosamente nele por circunstâncias exteriores não controláveis por elas." (REGO; PINZANI, 2009, p. 107).

5 Cito como exemplo em nosso país, o artigo 225, \$1 VII da Constituição Federal de 1988, que diz: proteger a fauna e a flora, vedadas, na forma da lei, as práticas que coloquem em risco sua função ecológica, provoquem a extinção de espécies ou submetam os animais a crueldade. E também o Art. $32-$ Dos Crimes Contra a Fauna, da lei 9.605/98, classifica como crime praticar ato de abuso, maus-tratos, ferir ou mutilar animais silvestres, domésticos ou domesticados, nativos ou exóticos. O Decreto Federal 24.645/1934 (Lei de Proteção aos Animais) decreta em seu Art. $1^{\circ}$, que todos os animais existentes no país são tutelados pelo Estado. O Art. 3ํtraz 31 incisos sobre o que caracteriza práticas de maus tratos aos animais. 